\title{
Correction to: Eculizumab treatment and discontinuation in pediatric patients with atypical hemolytic uremic syndrome: a multicentric retrospective study
}

\author{
Esra Baskin ${ }^{1} \cdot$ Kibriya Fidan ${ }^{2}$ (1) Bora Gulhan ${ }^{3} \cdot$ Kaan Gulleroglu $^{1} \cdot$ Nur Canpolat $^{4} \cdot$ Alev Yilmaz $^{5} \cdot$ Gonül Parmakiz $^{6}$. \\ Zeynep Birsin Özçakar ${ }^{7}$. Fatih Ozaltin ${ }^{3}$. Oguz Soylemezoglu ${ }^{2}$
}

Published online: 7 February 2022

(c) The Author(s) under exclusive licence to Italian Society of Nephrology 2022

\section{Correction to: Journal of Nephrology https://doi.org/10.1007/s40620-021-01212-w}

The author name and sur name of the author Zeynep Birsin Özçakar has been incorrectly published. The correct name has been provided below:

Zeynep Birsin Özçakar

The original article has been corrected.

Publisher's Note Springer Nature remains neutral with regard to jurisdictional claims in published maps and institutional affiliations.

The original article can be found online at https://doi.org/10.1007/ s40620-021-01212-w.

\section{Kibriya Fidan}

kibriyafidan@yahoo.co.uk

1 Department of Pediatric Nephrology, Başkent University, Ankara, Turkey

2 Department of Pediatric Nephrology, School of Medicine, Gazi University, Ankara, Turkey

3 Department of Pediatric Nephrology, Hacettepe University Faculty of Medicine, Ankara, Turkey

4 Department of Pediatric Nephrology, Istanbul University-Cerrahpasa, İstanbul, Turkey

5 Department of Pediatric Nephrology, Istanbul University Istanbul School of Medicine, İstanbul, Turkey

6 Department of Pediatric Nephrology, Başkent University Adana Dr. Turgut Noyan Training and Research Center, Adana, Turkey

7 Department of Pediatric Nephrology, Ankara University Medical School, Ankara, Turkey 